\title{
ALTERNATIVE SOLUTION OF
}

A MILLING HEAD HOUSING USING THE COMPUTER AIDED SYSTEMS

VACLAVA LASOVA ${ }^{1}$, PETR BERNARDIN $^{1}$, MARCEL SVAGR ${ }^{1}$, JIRI
KUBICEK $^{2}$

${ }^{1}$ University of West Bohemia in Pilsen, Faculty of Mechanical Engineering, Department of Machine Design

${ }^{2} \mathrm{SMT}$ a.s., Research and Development Department

DOI : 10.17973/MMSJ.2021_03_2021001

berny@rti.zcu.cz

The aim of this work was design of alternative solution of milling head housing with help of topology optimization. Mechanical properties of new alternative housing solution (specifically a stiffness) are based on the existing milling head IFVW10x manufactured by the ŠMT a.s. company. The stiffness of existing milling head was determined using KISSsys calculation software, as well as the stiffness of the milling head with the alternative housing solution. The special "Guayan reduction" tool (Siemens NX software) was used to obtain the partial stiffness of the housing and to determine its influence on the stiffness of the whole assembly.

KEYWORDS

Finite element model, stiffness analysis, bearing, housing, spindle, Guayan reduction, Static condensation, topology optimization

\section{INTRODUCTION}

High demands are currently placed on production in general. Emphasis is mostly placed on increasing production efficiency in the form of reducing costs, increasing productivity, optimizing the properties of parts and equipment. One of the main customer requirements is the reduction in delivery time of an equipment. This is resulting in reduced time for the design and development of equipment. In the ideal state, a large number of advanced analyses (stiffness, strength analyses, modal analyses, temperature analyses) are required for predicting the behaviour of the machine, equipment, or products in general. This is a very time-consuming process. Therefore, the designer is faced with the choice of which analyses to perform and which not. His main goal is the comprehensive utilization of all available tools as productively as possible (respecting the time). This is also applied to the milling head design [Lašová 2011]. The performing of separate analysis of individual components (main drive, parts of the frame, bearings, shafts, gears) is no longer sufficient [Lašová 2015, Bernardin 2017]. It is appropriate to implement the shaft behaviour (displacement, rotation) in the gear calculation, or stiffness of the housing of the gearbox (eventual of milling head). Accordingly, the utilization of the special singlepurpose (SSP) programs is offered (KISSsys, MITCalc, etc.). In our specific case, the KISSsys calculation software [KISSsoft AG19982014] allows an implementation of the housing stiffness in a stiffness calculation of the milling head assembly. Reduced stiffness matrix of the housing was obtained by specific modification of the stiffness matrix, by the "Static Condensation" (SC), or "Guyan Reduction" (GR) process. This matrix is an input to the KISSsys calculation. The main goal of this research was the utilization of this approach. The substantial contribution of this work was grounded in comprehensive evaluation of the stiffness of the milling head, including all partial stiffness (spindle, bearing, housing). The influence of the partial stiffness of the housing on the total stiffness (related to the milling head) was determined using performed analyses (FEM, GR, KISSsys calculation). Predicted behaviour can be further used in other analyses and simulations, for example the process of recovery of devices using "Digital twin technology" [Janda 2019], other advanced analyses (thermal, geometrical optimization, topology optimization [Sedláček 2019]), or virtual machining simulation (CAM). At the end of this work, the acquired knowledge is used for designing an alternative solution of the housing with the unique shape intended for 3D printing production using topology optimization process. The mechanical properties of the new design should correspond to the results of the original housing.

\section{FINITE ELEMENT MODEL}

The common finite element model is defined using the matrix equations, which describes structural behaviour of whole model. The static equilibrium of finite element model shows the Equation 1.

$\left[\boldsymbol{K}_{\boldsymbol{g} \boldsymbol{g}}\right]\left\{\boldsymbol{u}_{\boldsymbol{g}}\right\}=\left\{\boldsymbol{P}_{\boldsymbol{g}}\right\}$

where the $K_{g g}$ is a global stiffness matrix and includes a system of the matrix stiffnesses of all elements. The $u_{g}$ is a global displacement. The $P_{g}$ is a vector of the loads applied to all scalar and grid points of the model. It is necessary to organize and reduce the matrix during the Structural linear static (SLS) calculation in general. The matrix reduction process describes the division of the global stiffness matrix and the elimination of individual members with the same criterion. All global parameters are belonging to the "g-set" (global set), which is the highest set level. All members selected based on the same criteria can be marked as other set or subset, marked with the appropriate letter. For example, the $\mathrm{m}$-set includes all dependent degrees of freedom (DOF) of all multipoint constraints. By reducing the global stiffness matrix using the $\mathrm{m}-$ set DOFs, the matrix is condensed into the independent $n$-set DOFs. This process called Partitioning can be repeated for other sets at lower level, which is shown in Table 1, where s-set represents single point constraint relations.

\begin{tabular}{|l|l|l|l|l|}
\hline \multicolumn{5}{|c|}{ Partitioning Operations } \\
\hline g-set & - & m-set & $=$ & n-set \\
\hline n-set & - & s-set & $=$ & f-set \\
\hline f-set & - & o-set & $=$ & a-set \\
\hline a-set & - & r-set & $=$ & l-set \\
\hline
\end{tabular}

Table 1. Partitioning Operations

The f-set includes free DOFs of the model. The f-set is further reduced using the SC process and divided into the o-set and the a-set. The o-set DOFs are omitted from the analysis, whereas the analysis is performed at the a-set partition. The $r$-set is a reference set, including a rigid body support and the "leftover" I-set remains.

\subsection{STATIC CONDENSATION}

The "Static Condensation" (SC) belongs to the reduction techniques as well as "Dynamic Reduction "[Đukić 2012], „Hybrid Reduction “[Mashayekhi 2019], “System Equivalent Reduction Expansion Process “, or "Improved reduced system "[Li 2017]. The SC includes the same matrix operations 
(reformulation and partition) as the „Guayan reduction” (GR) method, which is therefore an interchangeable alternative. Solving problem using the GR can be divided into three steps:

1. The $\mathrm{f}$-set reduction (obtaining a-set)

2. Performing the solution for a-set displacement $u_{a}$

3. Performing the solution for o-set displacement $u_{o}$

The relationship between stiffness, displacement and applied load using free (non-constrained) structural coordinates is expressed by the equation 2 .

$\left[K_{f f}\right]\left\{u_{f}\right\}=\left\{P_{f}\right\}$

where the $K_{f f}$ is the stiffness matrix considering free DOFs, the $u_{f}$ are displacements and the $P_{f}$ are loads (both at free nodes).

$\left\{u_{f}\right\}=\left\{\frac{u_{a}}{u_{o}}\right\}$

The equation 3 describes the partitioning process of the f-set displacement $u_{f}$ into a-set displacement $\left(u_{a}\right)$ and o-set displacement $\left(u_{o}\right)$. The equation 4 was determined by modifying the equation 2 with help of the partitioned $u_{f}$ (Equation 3 ).

$\left[K_{f f}\right]\left[u_{f}\right]=\left[\begin{array}{ll}\overline{K_{a a}} & K_{a o} \\ K_{o a} & K_{o o}\end{array}\right]\left\{\frac{u_{a}}{u_{o}}\right\}=\left\{\frac{\overline{P_{a}}}{P_{0}}\right\}$

It is possible to express the lower and upper part of the equation separately (see eq. 5 and eq. 6).

$\left\{u_{o}\right\}=\left[G_{o a}\right]\left\{u_{a}\right\}+\left\{u_{o o}\right\}$,

$\left\{u_{a}\right\}=\left[K_{a a}\right]^{-1}\left\{P_{a}\right\}$,

where the particular members of the equation are expressed using equation 7 - 10 .

$\left[G_{o a}\right]=-\left[K_{o o}\right]^{-1}\left[K_{o a}\right]$

$\left\{u_{o o}\right\}=\left[K_{o o}\right]^{-1}\left[P_{o}\right]$

$\left[K_{a a}\right]=\left[\overline{K_{a a}}+K_{a o} G_{o a}\right]$

$\left\{P_{a}\right\}=\left[\overline{P_{a}}+G_{o a}^{T} P_{o}\right]$

Only one-step procedure is needed for performing the common SLS calculation using the equation 1 . The results obtained during the GR are exact, but the procedure is not recommanded for SLS analysis. This could be caused by the time and disk space consuming three-step solution process. However the GR uses the reduced stiffness matrix, the additional decomposition results in one more matrix $K_{o o}$. The GR is an essential part of the analysis using the "Superelements".

\subsection{TOPOLOGICAL OPTIMIZATION}

The design of specific final product is very time consuming and often ineffective process. Many types of the optimization techniques were created and are usually used for meeting the requirements in field of stress, stiffness, reliability, or weight. Mathematically the optimization problem is usually formulated as a maximization (or minimization) of the objective function subject to constraints, described by eq. 11 and eq. 12 .

Find $X=\left\{\begin{array}{c}x_{1} \\ x_{2} \\ \vdots \\ x_{n}\end{array}\right\}$ by minimizing the $f(X)$,

subject to constraints $\begin{cases}g_{i}(X) \leq 0, & i=1,2, \ldots, m \\ h_{j}(X)=0, & j=1,2, \ldots, n\end{cases}$

where the $f(X)$ is called the objective function, the $X$ is a design variable, the $g_{i}(X)$ and the $h_{j}(X)$ are the inequality, or equality design constraints. Many types of structural optimization are known (Size, topography, composite, or topology optimization). The topology optimization (TO) contains two types of solution, the discrete approach and the continuum approach. The main goal of the discrete TO is the selection of the discrete set of elements, that should be present in the structure (eg. Truss beam design). The discrete TO includes many types of optimization procedures, for example Evolutionary Structural Optimization (ESO) [Xie 2010], Additive Evolutionary Structural Optimization (AESO) [Querin 2000a] or Bidirectional Evolutionary Structural Optimization (BESO) [Querin 2000b]. The continuum Element-based approach analyses the distribution of material in the design volume. The commonly used continuum TO are Solid Isotropic Microstructures with Penalization (SIMP) [Bendsøe 1989, Thou 1991], Rational Approximation of Material Properties (RAMP) [Stolpe 2001], Optimal Microstructure with Penalization (OMP) [Allaire 1997], Non-Optimal Microstructures (NOM) and Dual Discrete Programming (DDP) [Beckers 1997].

\section{STIFFNESS OF THE MILLING HEAD}

The GR was utilized by the stiffness evaluation of a milling head, which is commonly used attachment of horizontal milling and boring machine. For the purposes of this research, the milling head IFVW10x (Manufactured by ŠMT a.s.) was selected. (see Figure 1).

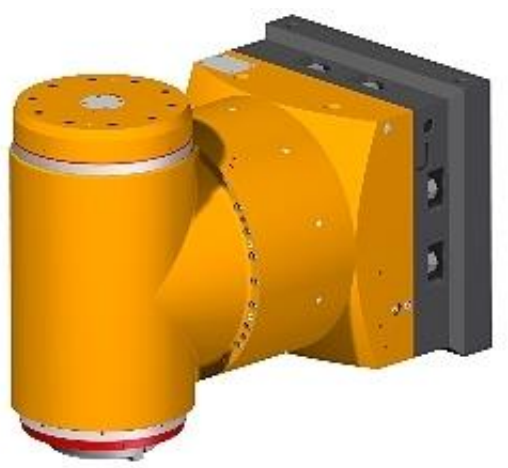

Figure 1. The milling head IFVW10x

The basic parameters of the milling head are shown in table 2 .

\begin{tabular}{|l|c|c|}
\hline & Value & Units \\
\hline Power & 67 & {$[\mathrm{~kW}]$} \\
\hline Maximal tourque & 4000 & {$[\mathrm{Nm}]$} \\
\hline Speed (At maximum torque) & 160 & {$[1 / \mathrm{min}]$.} \\
\hline Speed (At rated torque) & 2800 & {$[1 / \mathrm{min}]$.} \\
\hline Lifetime & 4000 & {$[\mathrm{hr}]$} \\
\hline Cutting diameter & 300 & {$[\mathrm{~mm}]$} \\
\hline
\end{tabular}

Table 2. The basic parameters of the milling head

\subsection{MILLING HEAD EVALUATION}

Milling head evaluation was performed using a combination of two computational software tools, specifically Siemens NX Simcenter software (NX) and KISSsys. A reduced stiffness matrix of an existing housing of the milling head was obtained using NX with the solver NX Nastran2019.1 - SOL101 Superelements. The housing was simplified and finite element model was created with help of 3D mesh tetrahedral elements. The first step of solving Superelements is the mentioned stiffness matrix reduction (GR) into predetermined points (figure 2 - Point 1 to 6). The points represent fictitious bearing centres. The points are connected by the rigid RBE2 elements to bearing surfaces. In those points was applied the „Fix Boundary Degree of Freedom”, all six DOFs were taken to ensure translation stiffness and torsional stiffness as well in stiffness matrix. Another boundary condition (affecting the resulting stiffness matrix) is the fixed 
translation constraint of the connecting flange surface (blue crosses in figure 2) and no other boundary condition was used.

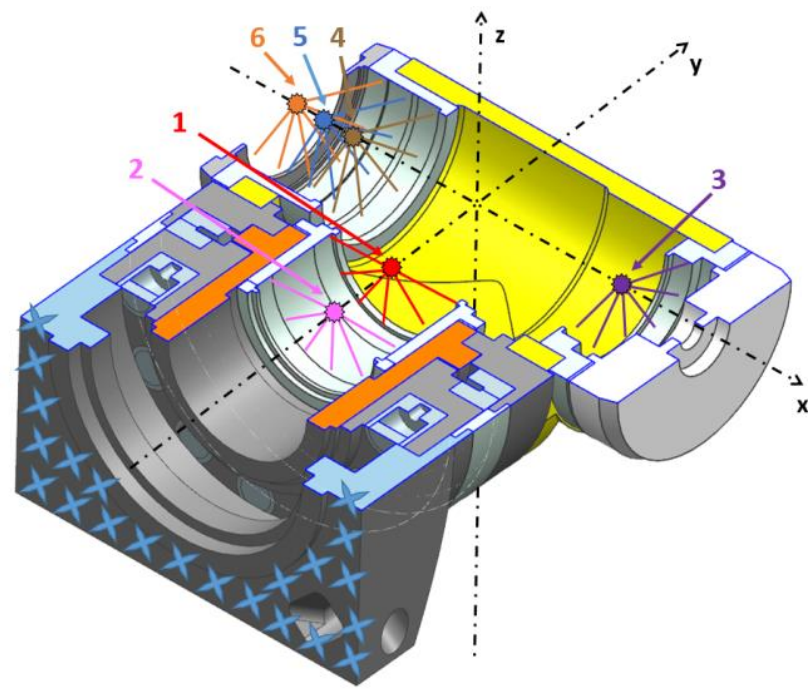

Figure 2. The housing of the milling head IFVW10x sectioned by plane $X Y$

The reduced stiffness matrix obtained by NX is exported to a file with *.pch extension according to KISSsys. It is necessary to ensure that the units from both software are set identically. The drive of the milling head was simply named Gearbox (GB). The calculation model of the GB was created in KISSsys software and it is shown in figure 3, where the Fo, Fr, Fa describes the cutting forces in particular direction and the "Pol" is the Point of interest.

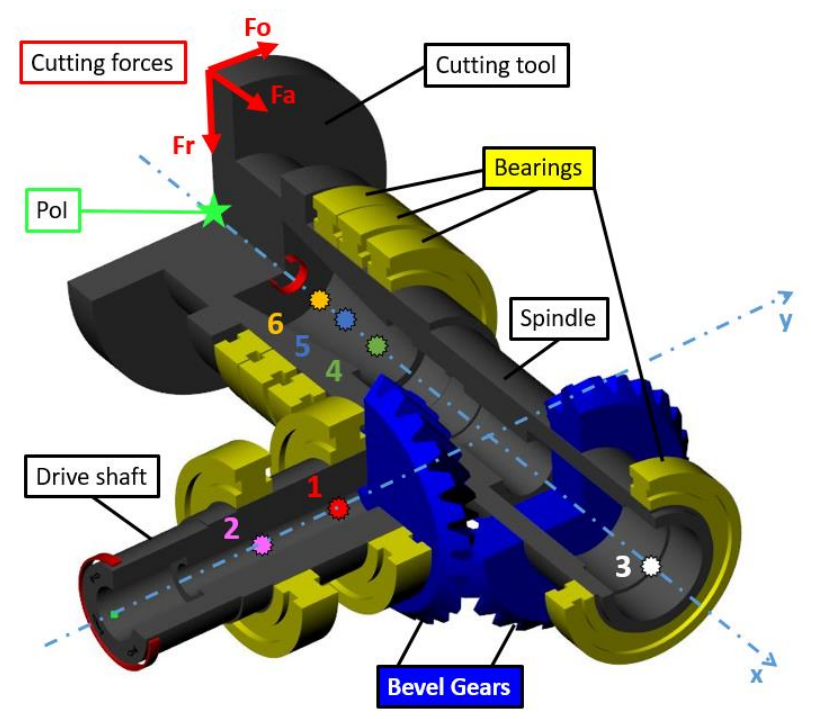

Figure 3. The drive of the milling head IFVW10x in KISSsys

The centre points of bearings are numbered $1-6$. The first calculation was performed without the influence of the stiffness of the housing. Second calculation was performed using the reduced stiffness matrix gained by NX. The influence of the housing stiffness is determined by comparing results of the two calculations (first and second). For the purpose of stiffness evaluation, the displacements and corresponding forces in the point marked as "Pol“ were tracked. The entered cutting forces are based on roughing operation with a milling tool (described in table 2). The second calculation was based on the same model as the first calculation, but the reduced stiffness matrix was imported. The stiffness was assigned to the „Housing" feature in the KISSsys software and it was included in calculation as an input parameter. The origins and the coordinate systems of the housing and the GB were set equally.

\subsection{ALTERNATIVE MILLING HEAD SOLUTION}

In this case, the TO continuum approach with method SIMP was used. TO was performed using the solver "NX Nastran 2019.1 SOL200 Topology optimization". Boundary conditions were set as follows:

- Fix translation at connecting flange

- Reaction forces in centre points of bearings (gained from KISSsys)

- Maximum allowable displacement in centre points of bearings (gained from KISSsys)

The modified volume of the housing was chosen as the design area. The internal dimensions have been preserved and the external dimensions were limited by the working space of the milling head. The volume under bearings and the volume of connection flange were chosen as the frozen area (see figure 4). Minimization of the compliance was set as an objective function. Maximum allowable weight of the design area was set as the design constraint. The SIMP Penalty value was set to three for solution of the TO. Tree manufacturing constraints were chosen:

- Planar symmetry (plane XY)

- Checker Boarding Control

- Minimum member size

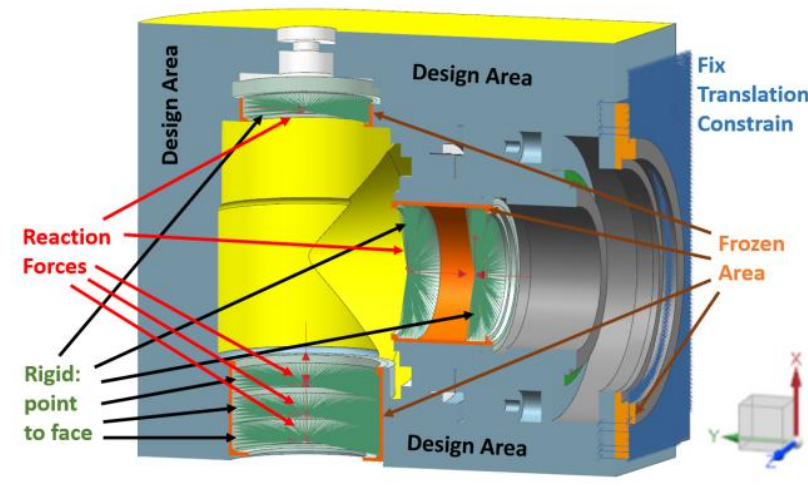

Figure 4. The idealized housing model used for TO

\section{RESULTS AND DISCUSSION}

\subsection{Reduced stiffness matrix determined by GR}

The reduced matrix of the housing related to the centre of bearing 1 is shown in table 3 .

\begin{tabular}{|c|c|c|c|c|c|c|}
\hline \multicolumn{7}{|c|}{ Stiffness Matrix [N/m] } \\
\hline & $d X$ & $d Y$ & $d Z$ & $r X$ & $r Y$ & $r Z$ \\
\hline P1-FX & $3.1 \mathrm{E}+10$ & $3.5 \mathrm{E}+08$ & $1.6 \mathrm{E}+07$ & $2.9 \mathrm{E}+05$ & $1.4 \mathrm{E}+06$ & $3.3 \mathrm{E}+07$ \\
\hline P1-FY & $3.5 \mathrm{E}+08$ & $4.2 \mathrm{E}+10$ & $8.7 \mathrm{E}+07$ & $1.3 \mathrm{E}+07$ & $8.5 \mathrm{E}+05$ & $2.2 \mathrm{E}+07$ \\
\hline P1-FZ & $1.6 \mathrm{E}+07$ & $8.7 \mathrm{E}+07$ & $3.0 \mathrm{E}+10$ & $4.9 \mathrm{E}+07$ & $6.6 \mathrm{E}+07$ & $1.1 \mathrm{E}+06$ \\
\hline P1-MX & $2.9 \mathrm{E}+05$ & $1.3 \mathrm{E}+07$ & $4.9 \mathrm{E}+07$ & $2.3 \mathrm{E}+08$ & $5.9 \mathrm{E}+05$ & $1.2 \mathrm{E}+05$ \\
\hline P1-MY & $1.4 \mathrm{E}+06$ & $8.5 \mathrm{E}+05$ & $6.6 \mathrm{E}+07$ & $5.9 \mathrm{E}+05$ & $4.4 \mathrm{E}+08$ & $1.8 \mathrm{E}+05$ \\
\hline P1-MZ & $3.3 \mathrm{E}+07$ & $2.2 \mathrm{E}+07$ & $1.1 \mathrm{E}+06$ & $1.2 \mathrm{E}+05$ & $1.8 \mathrm{E}+05$ & $2.4 \mathrm{E}+08$ \\
\hline
\end{tabular}

Table 3. The reduced stiffness matrix for Point 1

The translational stiffness is located in the green frame and the rotational stiffness in the orange frame. The diagonal elements of the matrix, which are located at position xx (yy, zz) consists of the sum of the direct stiffnesses of all the elements meeting at node $x(y, z)$. The elements located at position $x y(x z)$ consists of the sum of the indirect stiffnesses related to nodes $x$ and $y(z)$ of 
all the elements joining node $x$ to $y(z)$. Matrices for all other points $(2-6)$ were set analogous.

\subsection{The results of TO}

The final optimized design was determined in the iteration step number 145 . The final structure weight is $513.7 \mathrm{~kg}$. The weight of the housing (idealized 3D model) of the original milling head was $516.5 \mathrm{~kg}$. The final smoothed result of the milling head housing (using TO) is shown in figure 5 and figure 6 .

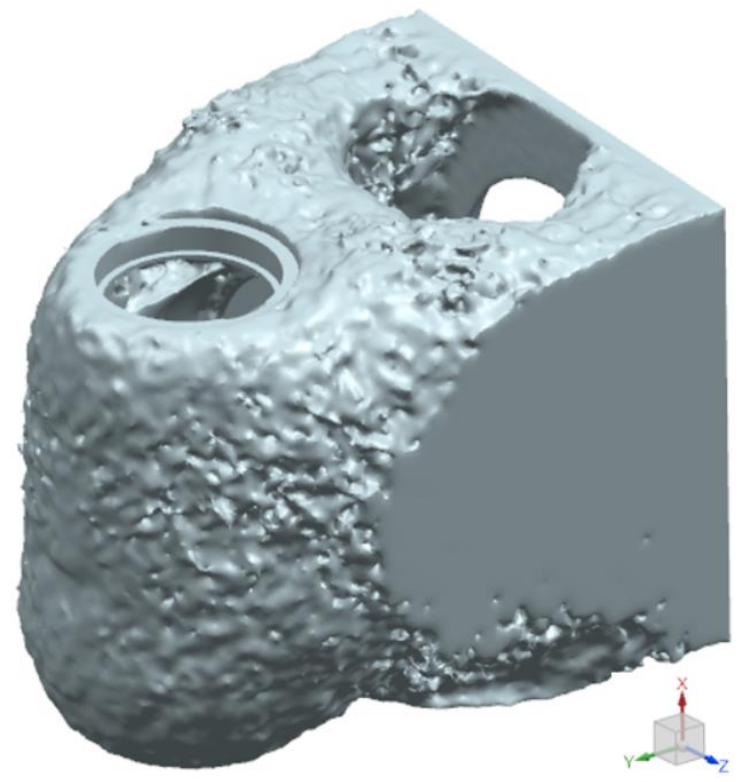

Figure 5. Smoothed result of the housing (using TO)

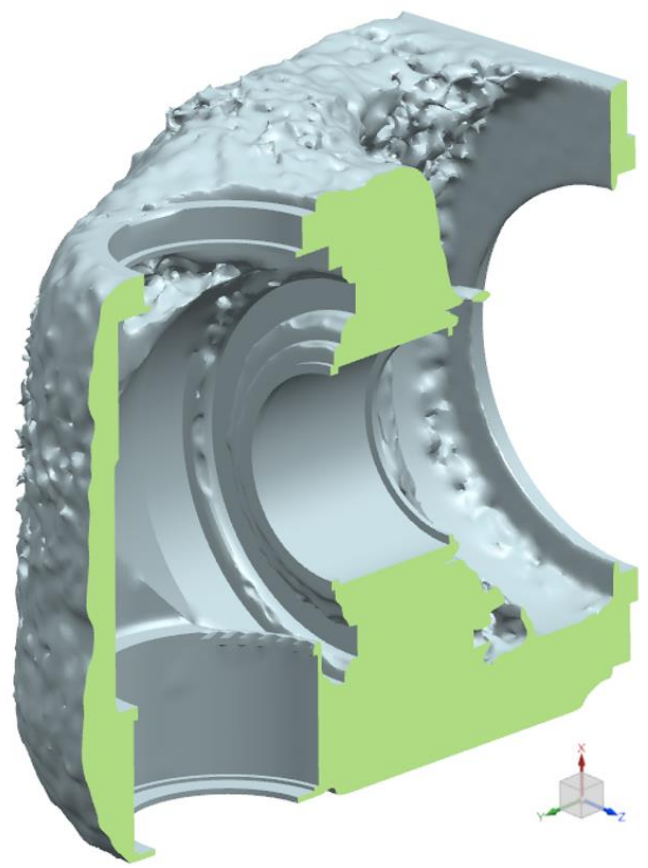

Figure 6. Smoothed result of the housing sectioned by plane XY

The bearing surfaces are clearly shown in figure 6 . These surfaces were omitted from the optimization process. The connecting flange is also preserved in order to connect to the existing machine. The resulting body was subjected to a verification calculation of TO. The displacements (stiffness) were subtracted from the Point 1 to the Point 6 according to the verification calculation. Stiffness of the structure is the nearly the same as by the housing of the original milling head.

\subsection{Comparison of Displacements in "Pol"}

The results of the displacements in the point marked as „Pol“ are shown in table 4.

\begin{tabular}{|c|c|c|c|c|c|}
\hline \multicolumn{6}{|c|}{ Displacements In "Pol" } \\
\hline \multicolumn{4}{|c|}{$\begin{array}{l}\text { Original Milling head IFVW10x } \\
\text { (original housing) }\end{array}$} & \multirow{2}{*}{\multicolumn{2}{|c|}{$\begin{array}{c}\text { Milling head with new } \\
\text { (alternative) housing } \\
\text { design }\end{array}$}} \\
\hline \multicolumn{2}{|c|}{ With housing } & \multicolumn{2}{|c|}{ Without housing } & & \\
\hline & {$[\mathrm{mm}]$} & {$[\mathrm{mm}]$} & [\%] & {$[\mathrm{mm}]$} & [\%] \\
\hline$d x$ & 0.063 & 0.060 & 4.4 & 0.060 & 4.9 \\
\hline$d Y$ & 0.047 & 0.045 & 4.0 & 0.046 & 2.5 \\
\hline$d z$ & 0.084 & 0.076 & 10.3 & 0.080 & 5.0 \\
\hline
\end{tabular}

Table 4. Displacements of in Point marked as „Pol“

These results were obtained by performing first and second calculation (calculation "With housing stiffness" and "Without housing stiffness"). The biggest difference between these two calculations is $10.3 \%$, see table 4 (In the $Z$ direction). The relationship between the displacement and the axial direction is shown in figure 7 . The new housing solution reduced the total displacements in the $\mathrm{X}$ direction is $4.9 \%$, in the $\mathrm{Y}$ direction $2.5 \%$ and in the $Z$ direction $5.0 \%$ see table 4 .

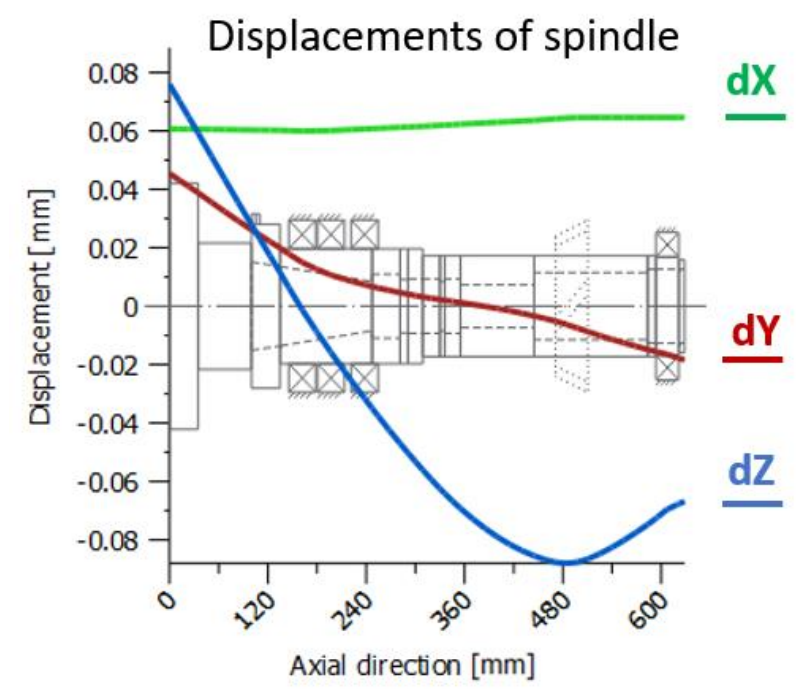

Figure 7. The relationship between the displacement and the axial direction

\section{CONCLUSIONS}

By using GR with superelemets, the preparation time for further calculations and optimizations is significantly reduced. The preparation of the FEM does require neither the mesh refinement nor the solution of stress concentrators, because they are irrelevant for the calculation of the stiffness matrix. The calculation of the stiffness matrix (using superelements) takes only several minutes. While the structural calculation of such a complex model takes place in the order of hours or days (not including time for thorough preparation of the FEM). The obtained stiffness matrix will be utilized for precising the resulting deformation on the spindle. In addition, it allows to change parameters of all main parts (housing, spinlde, etc.) for optimization the resulting deformation in a much shorter time. 
The new (alternative) solution of the milling head housing was designed with help of the TO. Its stiffness is almost identical to the original milling head solution (IFVW10x), approximately $5 \%$ better. The determination of the stiffness of whole miling head was performed with help of the KISSsys. The KISSsys calculation includes the housing stiffness, that was obtained by GR. The stiffness of the housing affects the resulting stiffness in the $Z$ direction (approximately $10 \%$ of the total resulting stiffness of the original milling head) in the "Pol”. In our specific case, the stiffness of the housing is an order of magnitude higher, than the stiffness of the other members. Therefore these members are more appropriate for the futher optimization. The determination or estimation of the price of the new housing or the retrun on investments of the millinmg head is not possible at this early design phase. The contribution of this research is new alternative design of the housing, assuming the utilization of an unconventional method of manufacturing technology (such as $3 \mathrm{D}$ printing), but above all significant reduction of its design time. The proposed approach (GR and KISSsys calculation) would be more helpful for milling heads with a larger tool extension (the distance from the clamping surface), for example extension milling heads or large size milling heads. The procedure described in this research provide a new alternative design of these milling heads while saving material, design time, and maintaining sufficient rigidity to proper function of main drive. Currently, these types of heads are usually calculated without the influence of the housing stiffness. The implementation of this approach to the extension milling heads is the goal of our next research.

\section{ACKNOWLEDGMENTS}

This paper has been supported by the project "Manufacturing engineering and precision engineering" funded as project No. CZ.02.1.01/0.0/0.0/16_026/0008404 by OP RDE (ERDF).

\section{REFERENCES}

[Allaire 1997] Allaire, G. The homogenization method for topology and shape optimization, in Topology optimization in structural mechanics, Springer, pp. 101-133, 1997.

[Beckers 1997] Beckers, M. Topology optimization involving discrete variables, in Proceedings of the second world congress of Structural and multidisciplinary optimization: May 26-30 1997, Zakopane, Poland, pp. 533-538, 1997

[Bernardin 2017] Bernardin, P. Strength analysis of pin connections using computer aided systems, MM (Modern Machinery) Science Journal, March, pp. 1773-1777. DOI: 10.17973/MMSJ.2017_03_2016103

[Bendsøe 1989] Bends $\varnothing$ e, M. P. Optimal shape design as a material distribution problem, Structural optimization, vol. 1, no. 4, pp. 193-202, 1989.

[Đukić 2012] Đukić, S. et al. Dynamic Model Reduction: An Overview of Available Techniques with Application to Power
Systems. Serbian Journal of Electrical Engineering. 9. DOI:10.2298/SJEE1202131D.

[Janda 2019] Janda, P. et al. IMPLEMENTATION OF THE DIGITAL TWIN METHODOLOGY, Proceedings of the 30th International DAAAM Symposium "Intelligent Manufacturing \& Automation", October 2019, pp. 533-538, DAAAM International, DOI: 10.2507/30th.daaam.proceedings.072

[KISSsoft AG1998-2014] KISSsoft, Bubikon: Available at: www.kisssoft.ch/english/downloads/, 1998-2014

[Lašová 2011] Lasova, V. Method of finite elements in calculations of machine tools. Pilsen: University of West Bohemia, 2011. ISBN 978-80-261-0008-9 (in Czech)

[Lašová 2015] Lašová, V. et al. COMPARISON OF CAPABILITIES OF FINITE ELEMENT METHOD AND SPECIALIZED SOFTWARE PROGRAMS IN EVALUATION OF GEARS, MM (Modern Machinery) Science Journal, June 2015, pp. 610-612. DOI: 10.17973/MMSJ.2015_06_201515

[Li 2017] Li, D. Discussion of Model Reduction and Reservation. Procedia Engineering. 188. pp. 354-361. 2017. DOI: 10.1016/j.proeng.2017.04.495.

[Mashayekhi 2019] Mashayekhi, F. et al. Hybrid reduction of mistuned bladed disks for nonlinear forced response analysis with dry friction, International Journal of Non-Linear Mechanics, Volume 116, 2019, pp. 73-84, ISSN 0020-7462, DOI: 10.1016/j.jinonlinmec.2019.06.001.

[Querin 2000a] Querin, O.M. et al. Evolutionary structural optimisation using an additive algorithm, Finite elements in Analysis and Design, vol. 34, no. 3-4, pp. 291-308, 2000.

[Querin 2000b] Querin, O.M. et al. Computational efficiency and validation of bi-directional evolutionary structural optimisation, Computer methods in applied mechanics and engineering, vol. 189 , no. 2, pp. 559-573, 2000.

[Stolpe 2001] Stolpe, M. et al. An alternative interpolation scheme for minimum compliance topology optimization, Structural and Multidisciplinary Optimization, vol. 22, no. 2, pp. 116-124, 2001.

[Sedláček 2019] Sedláček, F. et al. OPTIMIZATION OF MAIN PARTS OF A HEAVY DUTY CNC MACHINE CENTRE USING A TOPOLOGICAL OPTIMIZATION, Proceedings of the 30th International DAAAM Symposium "Intelligent Manufacturing \& Automation", October 2019, pp. 525-532, DAAAM International, DOI: $10.2507 / 30$ th.daaam. proceedings.071

[Thou 1991] M. Zhou et al. The COC algorithm, Part II: Topological, geometrical and generalized shape optimization, Computer Methods in Applied Mechanics and Engineering, vol. 89, no. 1-3, pp. 309-336, 1991.

[Xie 2010] Xie, Y. M. et al. Recent developments in evolutionary structural optimization (ESO) for continuum structures, in IOP Conference Series: Materials Science and Engineering, vol. 10, p. 012196, 2010. 


\section{CONTACTS:}

prof. Ing. Václava Lašová, Ph.D.

University of West Bohemia, Department of Machine Design, Faculty of Mechanical Engineering Univerzitni 22, Pilsen, 306 14, Czech Republic

tel.: +420 37763 8264, e-mail: lasova@kks.zcu.cz

Ing. Petr Bernardin, Ph.D.

University of West Bohemia, Department of Machine Design, Faculty of Mechanical Engineering Univerzitni 22, Pilsen, 306 14, Czech Republic

tel.: +420 37763 8263, e-mail: berny@kks.zcu.cz

Ing. Marcel Švagr

University of West Bohemia, Department of Machine Design, Faculty of Mechanical Engineering Univerzitni 22, Pilsen, 306 14, Czech Republic

tel.: +420 37763 8299, e-mail: svagrm@kks.zcu.cz

Ing. Jiří Kubíček

ŠMT a.s., Research and Development Department

Tylova 57, 30100 Pilsen, Czech Republic

tel.: +420 378136 781, email: jiri.kubicek@skodamt.com 